\title{
Virtual Reality and Reproduction of Sociality: Experience of Social and Philosophical Analysis
}

\section{Aklim Khatypovich Khaziev}

\author{
Kazan (Volga Region) Federal University
}

Email: aklim.haziev@yandex.ru

Natalia Olegovna Khazieva

Kazan (Volga Region) Federal University

Email: apotre@mail.ru

\section{Elena Vladimirovna Kliushina}

Kazan State Power Engineering University

Email: elv12006@rambler.ru

Doi:10.5901/mjss.2014.v5n23p1833

\begin{abstract}
The article considers the situation in the community determined by the philosophers as a "social death." What does it mean? Is there a way out of this situation? If so, what is it? These are the questions the authors look answers for. According to the authors, the metaphor "social death" is the acknowledgement of the extreme exhaustion of the modern society's humanistic potential. Addressing the issue, by the authors, is in virtualization, i.e. the process of creation of the virtual worlds, where the man "gets" himself/herself and the society to the absolute completeness. The man returns to the world of physical reality, willing to improve it and to live in it as he/she would do in his/her dreams. And so goes permanently.
\end{abstract}

Keywords: Virtualization, virtual social space, real(actual) social space, socialization, personality.

\section{Introduction}

Philosophers beat the alarm, announcing the "death of the social"( Baudrillard J., 1998). There is a situation in the society when a person comes close to the threshold and by reaching which he/she will cease to be himself/herself, i.e. the man (In any culture, there are ideas about the horizon, having passed which a person ceases to be the man. They quite clearly recorded by both means of "high" and means of "low" culture. For example, in the vernacular Russian language the following types of expression are used, i.e. "werewolf", "vampire", "beast in a human form", etc. At the level of the philosophical reflection, the one-dimensional transformation of a human being, or even death of the subject is stated). It seems, indeed, that even a little bit can end the history of the mankind.

Being unanimous in willing to prevent this, philosophers may radically differ from each other in the determination of the causes and, therefore, the ways to prevent this danger. All ultimately rest on the understanding of the man and the society, the nature of which, depending on the metaphysical preferences of a thinker, can be interpreted in two ways, i.e. either they turn out to be the being created by the God, or they are the result of the evolution of the nature (anthropogeny). In the first case, falling away from the Creator is considered to be the main reason for leading away from the face of human, and for the transforming the society into a herd. One of the examples of this approach is the biblical story of Sodom and Gomorrah (Holy Bible: English Standard Version, 2008).

In the second case, the cause must be sought in the society itself, and in the social relationships. Obviously, it is their nature that leads to the same result, i.e. the man betrays his/her nature. In our opinion, the famous words of Aristotle about the man that betrayed his nature due to the fact that he ceased to communicate with his own kind can be considered as an example of the second approach (Aristotle, 1983, pp. 375-644).

The conclusion is that the problem lies in the reproduction of the sociality aimed at the disclosure of the essential powers of the man.

Of the many ways (economic, political, and technical/technological) that generate similar public relationships, the 
authors of this article focused on the virtualization. Not only this follows the spirit of the philosophical understanding of the world and the man's place in it, because it claims to solve metaphysical problems, but it also reflects the creative role of the man in the historical process (It should be emphasized that most of the works devoted to the problem of the virtual interpret it in the technical and technological way linking it with the Internet space and computer games. Of the works that demonstrate the philosophical understanding the following authors could be named: Calvert SL The Social Impact of Virtual Reality (Calvert S.L., 2002, pp. 212-228); Chesher C. Colonizing Virtual Reality. Construction of the Discourse of Virtual Reality (Chesher C., 1994); Heim M. The Metaphysics of virtual reality (Heim M., 1991, pp. 27-33); Riva G., Davide F. Virtual Reality as communication tool: a socio-cognitive analysis (Riva G. and Davide F., 2001, pp. 47-56); Schroeder R. Possible Worlds. The Social Dynamic of Virtual Reality Technology (Schroeder R., 1996, pp. 203); Zizek S. Slavoj Zizek: The Reality of the Virtual (Zizek S., 2001)).

\section{Body}

By highlighting the potential and the actual, the possible and the real, the necessary and the random the philosopher offers to the man and the society a picture of a complex structured world, different facets of which while opposing each other comprise a unity at the same time. But the mind of the philosopher is not limited to a dissection of the unity into pieces and assembling complex from simple. Correlating all aspects of the reality with each other, the mind aims at searching the hidden reality's mechanisms considering them the priority for the understanding of the Universum(Lat.) functioning, and puts the man in between the matter and the due. The world of things and the everyday existence force the man to go into the world of due, where he/she lives a virtual life. However, the virtual existence cannot last forever and the man returns to the real world. And so happens permanently. The consequences of such journey are ambiguous for the man and for the society except possibly one, they are both in a state of perpetual change, and renewing identities. The virtual world being a creation of the human spirit is diverse and manifests itself at the different levels which, of course, must be considered in order to adequately represent its impact on the real world.

One (the first) virtual reality, as a product of the social activities of all previous generations, is the objective spirit in relation to each new generation of people. It is located "above" the man as, eventually, his repeatedly reinforced views of the world, of the good and the evil, of the beautiful and the ugly, of himself, of the existence and the due, as something "above" his/her ancestral. One can say that this virtual reality lives "its own life", and the man is unable to influence it directly, but only indirectly.

In this case, the actual (present) reality which the man resides in is made up of the virtual reality world's phenomena such as the world created by the God; or the form of tradition arising out of a particular culture and language features; the very existence of the absolute spirit presupposes an inherently lower subjective spirit and the natural reality. Perhaps the most important feature of this virtuality is that by dictating the rules and standards of conduct, it turns an individual into a member of society. But this process is self-contradictory, i.e. whatever degree of generality the norms and standards are established with, they always have specific historical and cultural refraction. And therefore, not only they unite, but also separate people, based, for example, on ethno - confessional "apartments". Space-time objectification of the virtual sociality as something "above" generic can be progressive but also may act as a force suppressing development of the society. We believe that this is what Nietzsche wrote, determining social role of the religion and claiming that the latter can lead their followers to either win or to stagnation and defeat (Nietzsche F., 2011, pp. 263-330).

Also, it is necessary to distinguish the virtual reality itself and the man's subjective perceptions of it. The man can never fully appreciate it in his/her earthly existence conditions; the man will always be lacking moral or intellectual forces that would put him/her up to the level of mere contemplation of the sublime as such. Based on his/her understanding, on the front line the man will always put his own idea of the due, the perfect, the divine. Non-compliance of the extremely sublime and the truly genuine and understanding of them is shown, for example, in the works of Plato, Hegel.

So appears the (general) human ("earthly") understanding of the due as some overriding order. In the minds, the sublime and the universal are reborn (degenerated) into the due, and are distorted by the man itself. So, everyone has his/her own truth and his/her own order of things.

Of course, this individual understanding of the due falls into a state of imbalance with the visible (present) reality. It turns out that things are not the same as they ought to be (according to the man himself). The world (earthly) order turns out to be not identical to the space and the universal ones. Following the example of the religion it may look as follows. The God exists, it is pure faith. This is followed by an individual's perception of the God and the divine manifestations, and this is the religion. And then, a mismatch of the present, profane world of the man's conceptions of the divine world as it ought to be. Here arises another (second) virtual reality. In order to realize its essence in such highly complex and controversial for the individual conditions and go through the process of socialization to the end (because the first virtual 
reality is not enough), the man must appeal to his/her own inner world. In this sense, the second virtual reality compared to the first is subjective, and is generated by a single person. However, it does not completely belong to the man. It is largely a reflection, and in this sense, is a product of the imperfect world surrounding the man.

At all times and to various extents every person had created the second virtual reality being aware of it or not, deliberately (with a specific intent), intuitively or not willing it at all, almost entirely, or only partially mimicking the surrounding reality.

A lot of threats to the man and his/her personality lurk in this substitution of the two realities, the actual and the virtual. The man can become isolated in his/her own virtual world, immerse himself/herself in it completely; and then the virtual world will become his/her only real and significant world; and the actual (real) world will become the secondary one. An example of this would be a generalized character of the undergrounder of "Notes from Underground" by Dostoevsky. This man prefers his own contrived (virtual) underworld to the real one. A few "outs" into the life can cause great pain: "In my underground dreams... I have managed to corrupt myself morally, and am so unused to "real life", so it crushed me so hard I could hardly breathe " (Dostoevsky F., 1973, p. 176]. But sometimes the virtual world can defeat its creator, obsessing him/her to the extent that he/she cannot find a way to return to the real world.

However, it is in the human nature to create virtual reality not only for himself/herself. The virtual worlds can be designed for others too. As it is well known, that a substance is the only thing that is self-sufficient, and this is "the absolute subject". Everything else is the subject in one respect, and the object in another.

Whatever guides a creator (sincere desire to help close ones, or in pursuit of selfish interests), those to whom his work is intended act as the object of manipulation in any case. Yet the motive of his/her action is very important. An example of the creator with good intentions is, from the point of view of Marxism, the Communist Party, which must lead the proletariat to "the bright future". After all, the working class on its own can only develop trade - union consciousness that promotes the conservation of the present exploitative social relationships. Having realized and imbued with its true interests, the proletarians become the gravediggers of the capitalism and begin to build sociality that will reveal the essential powers of the man.

But there is a deliberate change, distortion of the real situation, when the creator of the virtual reality deliberately delude the society or the group of people; when an event is intentionally distorted, is painted in different colours, and is presented with a single selected side. This is done in order to achieve their own benefit in any of its manifestations. Of course, this requires a lot of economic, information and other costs. This, for example, can be done by dishonest politicians, manufacturers, advertisers and others. They may use, for example, media as a means for propagation of the virtual reality they have created and for the formation of a definite opinion of the society.

The actual appearances (forms) of the second virtual reality in the society can be ideologies, utopias, promotions, and other political propaganda, and much more. Of course, for this to happen there should be certain conditions, because in a strong and healthy society there shouldn't be any room for such provocation. Such ideas should fall on prolific, prepared soil, the soil that has already been "loosen" by the economic and the political instability and social afflictions. And then, as Marx pointed out: "... the theory becomes a material force ..." (Marx K. and F. Engels, 1955, p. 422).

Compared to the first virtual reality the second one is always active, even down to the aggression towards the man. Not having such a long history of formation and development as the first one, it can cause great damage to the society.

Let's take a look at yet another very important point. The second virtual reality is often played in front of the "face" of the society. Such is, for example, covering terrorist acts of the democracy which is, however, narrowly understood and is always implying its only right content favourable to its interpreter. Not less striking, but even more important for the socialization (the fate of the world in general) is the strongly imposed on society the idea that there is a so-called "highway of human civilization." It is presented as a kind of absolute value. Moreover, its adoption is not just desirable, but, in essence, is mandatory for all. And then it is no longer just a "so-called", but is the notorious value, because it coincides with the interests of the forces that dominate the political and military terms. They are the safeguards to ensure adherence to this "highway".

There is a double logic here. Anyone who creates the second virtual reality is set to hide the growing imbalance between the real world (the real situation, the way it actually is) and the virtual one (space "provided" for the existence of the society). All actions of the creator aim to create and to further preserve, to adopt, and to strengthen the contradictions of the two realities. We are facing the parallel existence of the world of the informed and acting ones and the world of the forced to live by the inculcated rules. Any "accepted" (by the leaders) attempts to change this situation only reinforce the division, creating an illusion of the movement and change. As an example of the latter can be an advertising campaign to increase consumption of goods, services, thoughts, ideas, etc.., and entertainment, while appealing to the society for the social activity and responsibility (political, economic, etc.)

But there is a reverse logic, i.e. the logic of the society. The society by its very nature tends to destruct such 
contradictions and inculcated conditions of the existence. But to discover this imbalance and to destroy the created virtuality isn't an easy task. Especially, when it really captured the minds of the people and began to produce its own specific benefits. The ability to recognize such artificial speculative construction, and moreover, to openly and freely say about it, isn't given to everyone. Only a small group of people that scrutinizing the structures and processes of the society is able to see the crashes and errors of the development, and to recognize that same virtual reality. Habermas called such people intellectuals. As an early warning system, it is their duty to intervene in time, send a signal when "things took a bad turn." Habermas talked about the intellectual ability to sense something important first: "He [intellectual] must be able to start to worry about certain critical trends while the rest are still going about their business as usual" (Habermas J., 2006, p. 8). The society that has such people is able to cope with its illnesses.

As a vivid example that demonstrates all of the above, we propose to consider the ideology, because its importance and influence on the modern society is very large. Ideology, as a certain system of views on social relationships and problems assumes the initial false understanding by the society of its actual conditions, the gap between the social reality and the distorted view of it.

S. Zizek draws our attention to the fundamental dimension of the ideology; it is not simply a "false consciousness", an illusory representation of reality, it is rather this reality which is already to be conceived as "ideological" - "ideological" is a social reality whose very existence implies the non-knowledge of its participants as to its essence. That is a social mechanism itself, homeostasis, which suggests that individuals "do not know what they are doing" (Zizek S., 1989, pp. 15-16). The ideology "works" only when it eludes the man, when the gap between the reality and the ideology disappears. Arisen as a result of specific historical circumstances, the ideology is distinguished by its creators as something eternal and unchanging. So the second virtual reality tries to replace the first virtual reality.

But the ideology does not come by itself. Ideologues are the main actors. They produce this same illusion; imaginary reality that stands out for reality itself, where the interests of the ruling class are claimed to be the interests of the whole society. Ideologists maintain social reality in an "as if ..." state, as if the president embodies the will of the people, as if the party expressed the objective interests of the working class ... (Zizek S., 1989, p. 34)

The virtual, in whatever form it appears, is created by the man, under specific historical conditions. Whatever the man and his/her historical time are, so are the virtual worlds created by the man. In this sense, the concepts such as, for example, "the man of Antiquity" and "the Society of Antiquity" and so on are rather relative. Serving as a theoretical constructs for the history generalization, they, under certain conditions, contribute to the dogma of the historical representations. It must be remembered that at the different stages of the same era the people and the society are different in relation to themselves in the past. This allows us to understand the contradiction of the historical process which, in particular, manifests in the well-known effect of the permanent return movement. And it turns out that the humanity decides in different situations the same problem, i.e. to be or not to be? That is the question. People wonder, with this in mind, and consider, for example, that the heirs must worship the same values as their parents. They are genuinely outraged when they find out that it is not quite the case, and a confrontation line "Fathers and Sons" arises, etc. Therefore, there should be a distinction between the man of the classical Antiquity, when he/she created virtual worlds, guided by the principle of "the man is the measure of all things!" and the man of the post-classical Antiquity, and especially, at the final stage of Antiquity. Creating virtual worlds, the man commits to the principle of "live quietly", and recognizes the supremacy of the fate and treats the subject-sense world as a place of temporary stay, living in the All in his/her feelings and thoughts. Hence, the fundamental difference between them as subjects of the history, they produce different types of sociality.

The above fully applies to the subsequent periods, including the present, determined by the philosophers as Postmodern. Therefore, the researcher faces the familiar questions, i.e. what is the nature of the man's interaction with his/her present social being? which virtual worlds does the Postmodern society lead the man to go to? how do the man and the society see themselves? The answer to these and similar questions allows one to understand the type and the forms of the sociality that will aid to (according to the post-modern man!) disclose the essential powers of the man.

In philosophy, there is a profound degree of ontological uncertainty, in which man lives today because the society is in a state of complete chaos and chaotic change. But this does not mean the absence of any qualitative certainty, because random changes only mean the absence of the predicted character. This state had been led to, as noted in the literature, by the extreme subjectification, atomization and relativisation of the social relationships and processes; the connections between the individual and the world appear as they broke off, there was a loss of stability of the social structures; and the feeling of instability and unreality of the social being had arisen (Emelin V.A., 1999; Altukhov B., 1992, pp. 59-72; Lyotard J.-F., 1998, pp.160). Moreover, the result could have been predicted a priori, as the process that led to it, was manageable, "The organized government, social and religious unions of our time are trying to force an individual not base his/her beliefs on his/her own thinking, but join those which they have intended for him/her" (Schweitzer A., 
2009, pp. 5-6). The great role in this belongs to media which by manipulating people replaces the world of live events with media ( Baudrillard J., 2006, pp. 268). They very cleverly "turn the conversation" from the message indicated in the report to the reporter itself. So there is a transition from the event itself to its image, the spectacle itself. The person, who receives only the cleverly arranged interpretation, but not the actual information about what is happening, is unable to go beyond this interpretation.

There is no vision, no understanding of the world's cultural, political and social events (The recent events in Ukraine, as they seem to us, are the complete confirmation of this). And there cannot be one due to the fragmentation of his/her thinking.

The gulf between the actual sociality and the virtual reality arises which, however, is overcome from time to time, and the social worlds intersect. The existence tragedy of the modern man manifests itself at this intersection. And the man at this point realizes his/her irrelevance in the world of the physical existence. In this world, the man is a random creature; he/she is real in the virtual world only, where the man is deliberately and constantly led to by the organized structures that represent the state power and are affiliated with it. In relation to the man, the power and its satellites are the total force, seeing a person not as a fellow citizen, but as a subject.

\section{Conclusions}

Humanity has faced this already, albeit in different forms, and historical and cultural contexts. History repeats itself. And if so, then the "social death" (i.e. the "end of history") is not the final verdict. The man still has chances to avoid irreversible changes, and the escape is in his/her own hands. The acknowledgement of the extreme exhaustion of the modern society's humanistic potential is, at the same time, an appeal of the intellectuals to the government and the fellow citizens to stop seeing each other as only a means to satisfy their own ambitions. Turning to the due, and "experiencing" everything that aids in disclosure of the human talents in the virtual world, the man still needs to go back to earth being convinced that he/she had found the answers to the sacramental questions: what does he/she know? what he/she dares to hope for? what must he/she do? And then history repeats again in all its contradictory glory!

\section{References}

Altukhov B. (1992). Contours of non-classical social theory. Social Sciences and Modernity. № 5, 59-72.

Aristotle. (1983). Politics, Works in 4 vols. V.4. Moscow. Mysl, 375-644.

Baudrillard J. (1998). In the Shadow of the Millennium. [Online] Available: http://www.egs.edu/faculty/jean-baudrillard/articles/in-theshadow-of-the-millennium/ (August 11, 2014)

Baudrillard J. (2006). Consumer Society: its myths and structures. J. Baudrillard. Translation from French, afterword and notes by E.A. Samarskaya. Moscow. Republic: The Cultural Revolution, 268.

Calvert S. L. (2002). The Social Impact of Virtual Reality. Handbook of Virtual Environment Technology. Ed. K. Stanney. Hillsdale: Lawrence Erlbaum Assoc., 212-228.

Chesher C. (1994). Colonizing Virtual Reality. Construction of the Discourse of Virtual Reality. Cultronix. [Online] Available: cultronix.eserver.org/chesherl (August 11, 2014)

Dostoevsky F. (1973). Notes from the Underground. In Complete Works in 30 volumes. V.5. F. Dostoevsky. Leningrad: Nauka, 99-179.

Emelin V.A. (1999). Virtual reality and simulacra. [Online] Available: emeline.narod.ru/virtual.htm (August 11, 2014)

Habermas J. (2006). The first to sense important. What distinguishes the intellectual J.. Habermas Translation from German by K. Levinson. "NZ", №3 (47), 5-13.

Heim M. (1991). The Metaphysics of virtual reality. Virtual reality: theory, practice and promise. Ed. K. Sandra Helsel and Judith Paris Roth. Meckler. Westport and London, 27-33.

Holy Bible: English Standard Version. (2008). Collins, 1170.

Lyotard J.-F. (1998). The postmodern condition. J.-F. Lyotard. Translation from French by N. Shmatko. Moscow. Inst experiment. Sociology, St. Petersburg. Aletheia, 160.

Marx K. and Engels F. (1955). Critique of Hegel's Philosophy of Law. In Works in 50 vols. 2nd ed. V.1. K. Marx and F. Engels. Translation from German by Institute of Marx-Engels-Lenin. Moscow. State Publishing House of Political Literature, 219-429.

Nietzsche F. (2011). Antichrist. In Collected Works in 5 vol. V.5. Nietzsche F. Translation from German by Y. Antonovskiy, J. Berman, V. Vainshtok and others. St. Petersburg.: Azbuka, Azbuka-Atticus, 263-330.

Riva G. and Davide F. (2001). Virtual Reality as communication tool: a socio-cognitive analysis. IOS Press: Amsterdam, 47-56.

Schroeder R. (1996). Possible Worlds. The Social Dynamic of Virtual Reality Technology. Oxford: Westview Press, 203.

Schweitzer A. (2009). I was born in a period of spiritual decline of humanity. Crisis of consciousness: a collection of works on "the philosophy of crisis" Moscow. Algorithm, 5-11.

Zizek S. (1989). The Sublime Object of Ideology. Verso. London, NY., 241.

Zizek S. (2001). Slavoj Zizek: The Reality of the Virtual. [Online] Available: www.youtube.com/watch?v=JKu_WUgyu3Y (August 11, 2014) 